\title{
Environmental Drivers and Network Structure of Hylid Anurans in Floating Meadows From Amazonian Oxbow Lakes
}

Lucicléia Railene Assis de Matos

Universidade Federal do Acre

Werther Pereira Ramalho ( $\square$ werther@institutoboitata.org )

Instituto Boitatá de Etnobiologia e Conservação da Fauna https://orcid.org/0000-0002-1049-2307

Filipe Viegas de Arruda

Instituto Nacional de Pesquisas do Pantanal

Karoline Ceron

Universidade Federal de Mato Grosso do Sul

Pedro Luna

Instituto de Ecologia

Lucena Rocha Virgílio

Universidade Federal do Acre

Lisandro Juno Soares Vieira

Universidade Federal do Acre

\section{Research Article}

Keywords: Floodplain, macroinvertebrates, ecological interactions, nestedness, modularity, river-lake connectivity

Posted Date: August 10th, 2021

DOI: https://doi.org/10.21203/rs.3.rs-748588/v1

License: (c) (1) This work is licensed under a Creative Commons Attribution 4.0 International License. Read Full License 
4 Lucicléia Railene Assis de Matos ${ }^{1}$, Werther Pereira Ramalho ${ }^{2,3^{*}}$, Filipe Viegas de Arruda ${ }^{3,4}$, Karoline Ceron ${ }^{5}$,

5 Pedro Luna ${ }^{6}$, Lucena Rocha Virgílio ${ }^{7,8}$, Lisandro Juno Soares Vieira ${ }^{1,8}$

7 Programa de Pós-Graduação em Ecologia e Manejo de Recursos Naturais, Universidade Federal do Acre,

8 69920-900, Rio Branco, AC, Brazil

$92 \quad 2$ Instituto Boitatá de Etnobiologia e Conservação da Fauna, 74093-250, Goiânia, GO, Brazil

$10{ }^{3}$ Laboratório de Biogeografia e Ecologia Aquática, Centro de Pesquisa e Pós-Graduação, Universidade Estadual 11 de Goiás, Campus Central, 75132-903, Anápolis, GO, Brazil

$12{ }^{4}$ Instituto Nacional de Pesquisa do Pantanal (INPP), Campus Avançado do Museu Paraense Emílio Goeldi, 13 78060-900, Cuiabá, MT, Brazil

14 5rograma de Pós-Graduação em Ecologia e Conservação, Universidade Federal do Mato Grosso do Sul, 15 79070-900, Campo Grande, MS, Brazil

$16 \quad{ }^{6}$ Red de Ecoetología, Instituto de Ecología A. C., 91073, Xalapa, VE, Mexico

$17 \quad{ }^{7}$ Centro Multidisciplinar, Universidade Federal do Acre, Campus Cruzeiro do Sul, AC, Brazil

$18{ }^{8}$ Laboratório de Ictiologia e Ecologia Aquática, Centro de Ciências Biológicas e da Natureza, Universidade 19 Federal do Acre, 69920-900, Rio Branco, AC, Brazil

$20 \quad$ * Correspondence author

21 E-mail: werther@institutoboitata.org

\section{Abstract}

Despite the increasing amount of knowledge available regarding the ecological interactions between species, the dynamics of anurans in aquatic environments are little explored and understood. In this way, our work aims to assess which factors influence the composition and the ecological interactions of hylid anurans in oxbow lakes in the middle Purus River, Amazonas. We sampled three lakes with high, medium and low levels of connectivity twice, once during the flood and then in drought hydrological regimes. Variations in the hylid anuran assemblages and ecological interactions were tested as function of environmental niche, food resources, level of connectivity and hydrological regime. The availability of environmental resources and the availability 
of food resources were the best factors that explain the distribution of hylid anurans, which were also highly

\section{Introduction}

44 In aquatic environments, changes in community structure are attributed to the sum of multiple processes, dependent on the variations between the hydrological regimes. The interactions between anurans, macroinvertebrates and macrophytes showed a modular and specialized structure, which varied according to the connectivity and hydrological regime of the lakes. Connectance showed an increasing trend from high to low connectivity lakes, suggesting that anurans had low trophic and environmental specialization in lakes with low connectivity. Hylids found in the lake of medium connectivity had higher values of trophic specialization and modularity. Our results illustrate the role of river-lake connectivity and annual hydrological cycle to maintain the aquatic biota and their interactions, and highlight the importance of floating meadows for the maintenance of biodiversity in floodplains.

Keywords: Floodplain, macroinvertebrates, ecological interactions, nestedness, modularity, river-lake connectivity including limiting and homogenizing effects of the species dispersion (Junk et al. 1989). Hydrological variation caused by the flood pulse in floodplains is a primary factor responsible for the ecological changes in aquatic biota (Junk et al. 2014), mainly mediated by the connectivity of river-lake systems (Thomaz et al. 2007). Floods create temporary connections between rivers and lakes which promote biological homogenization, through dispersion of biota and dilution of chemical components (Thomaz et al. 2007; Petsch 2016). When lakes are totally or partially isolated, local factors tend to influence variations in communities, including a reduction in depth, lake area, water transparency and dissolved oxygen content, as well as increase in nutrient concentration, electrical conductivity, pH and predation pressure (Thomaz et al. 2007; Scarabotti et al. 2011). Community structure therefore is influenced by how individuals from different species are filtered by the environmental constraints imposed by isolation, which may affect their ecological interactions and the dispersal capacity of each species (Hubbel 2001; Begon et al. 2006).

In tropical lakes (e.g., oxbow lakes) floating meadows are dominant floristic elements, which may be composed mainly by amphibian and free-floating plant species commonly known as macrophytes (Moura Júnior et al. 2015). The aquatic macrophytes tend to grow rapidly and undergo changes in their distribution due to the spatial and seasonal dynamics of the flood pulses (Junk et al. 1989), which ultimately influence the structure of aquatic communities (Junk et al. 1989). Such changes prompt the flow of nutrients and organisms, increasing 
61 spatial heterogeneity and availability of niches and resources between lakes (Thomaz et al. 2007). Because of these traits, floating meadows are ideal environments for reproduction, refuge and feeding of fauna species (Luz-Agostinho et al. 2009), which are important in the maintenance of the diversity of both macroinvertebrates (e.g., insects; Petry et al. 2003; Peiró and Alves 2006; Pelicice and Agostinho 2006) and vertebrates such as amphibians (Upton et al. 2014; Ramalho et al. 2016, 2018; Ganança et al. 2021). Floating meadows hosted unique communities of anurans (Ramalho et al. 2018), that use the floating environment for breeding, sheltering, foraging and dispersal (Hodl 1977; Hoogmoed 1993; Schiesari et al. 2003; Upton et al. 2014; Böning et al. 2017). The complex environment created by the unstable movement of floating meadows also act as a filter for anuran species, since the occurrence of anuran species is dependent on macrophyte composition and their vertical and horizontal structure (Upton et al. 2011, 2014; Ganança et al. 2021). In this sense, anuran communities in floating meadows are composed essentially by hylid (i.e., treefrogs) anurans (Upton et al. 2014; Böning et al. 2017; Ramalho et al. 2018). However, the role of macrophyte species composition (i.e., as potential environmental niche) and their associated macroinvertebrates (i.e., as potential food resource), as well as other local predictors (e.g., river-lake connectivity and hydrological regime), in the variation of anuran communities in floating meadows are still misunderstood, causing a gap in the knowledge as to the complex biodiversity in floodplains.

The use of tools from the Theory of Complex Networks has been useful to understand new aspects of the ecology and evolution of species assemblages. This is because these tools allow us to study how the species and their interactions are structured and how such structures vary over ecological gradients (Tylianakis and Morris 2017). Space may promote variation in network structure by affecting the likelihood of potential interactions (Guimarães Jr. 2020). Changes in the relative abundance or quality of the interaction partners can be explained by different factors, such as latitudinal patterns (Ceron et al. 2019). Tropical anuran-prey networks have high connectance, low modularity, and complementary specialization that are explained by the generalist diet of anurans (Ceron et al. 2019). However, despite the knowledge of the global pattern involving anuran networks, the knowledge regarding the properties of ecological interactions at local freshwater communities is still scarce. Indeed, we still lack theory and natural history to understand how the anuran assemblages interact with macrophytes assemblages in floating meadows (i.e., as an environmental resource for anurans) and their associated macroinvertebrates (i.e., as a part of the diet for anurans). Therefore, investigating how interactions are affected by changes in river-lake connectivity and hydrological regimes will increase of understanding of how freshwater communities are assembled and maintained. 

assemblages in floating meadows and their associated macroinvertebrates, and how these interactions are affected by changes in river-lake connectivity and hydrological cycle. Specifically, we tested the following hypotheses: (i) the environmental niche and available food resources are the primary predictors explaining the variation in composition of hylid anurans, although it should be dependent on both river-lake connectivity and hydrological cycle. We do expect this relationship because anurans associated with floating meadows are formed specially by species adapted to the flood pulse (Ramalho et al. 2018), which use the floating vegetation as calling and breeding sites (Hödl 1977; Upton et al. 2014; Ramalho et al. 2016), dispersion vectors (Schiesari et al. 2003; Böning et al. 2017) and potential source of food because they house a high diversity of macroinvertebrates (St. Pierre and Kovalenko, 2014). Thus, we sought to confirm that floating meadows contain enough environmental heterogeneity that induce to a non-random anuran assemblage structure (Ganança et al. 2021). If the environmental niche and food resource, as well as their variations throughout the hydrological cycle and lake-river connectivity, are important components to structure anuran communities, (ii) we expect that interactions between hylid anurans, macrophytes and macroinvertebrates vary in function of river-lake connectivity and hydrological regime. To this end, we identified the macrophyte species where each specimen was registered and analyzed its stomach content. According to the optimal foraging theory (OFT), when food is scarce, individuals expand their diet width to include less-favored items, which may expend their trophic niches and therefore affect their ecological networks (Emlen 1966; Robinson and Wilson, 1998). Thus, we predict that the oxbow lake more isolated and with low connectivity level has a high number of interactions (i.e., high connectance), in response to the lower supply of food, resulting in non-restrictive diets. In contrast, because more connected lakes have higher migration taxes (e.g., macrophyte species; Mormul et al. 2013), they can result in a great prey availability, leading to a maximum of prey selectivity and more specialized networks. We expect also that interactions between anurans and invertebrates would display modularity as it has been shown that such networks are not nested, but they show low levels of specialization and modularity and high connectance (Ceron et al. 2019). Across the different hydrological regimes and river-lake connectivity, we expect that such properties are going to vary, from more specialized interactions in the most connected lakes to

117 generalized interactions in the less connected lakes. 
Boca do Acre, State of Amazonas, Brazil (Figure 1). The Purus River basin is located in the northeast region of the Amazon, where the Purus River is one of the greatest tributaries of the Solimões-Amazonas system. This river is one of the longest rivers in South America, covering approximately 3,380 km, entering Brazil through the State of Acre, with its mouth in the river Solimões, state of Amazonas. It is classified as a white-water river (Sioli 1991) with meandering pattern and water rich in Andean sediments (Ríos-Villamizar et al. 2011). The climate of the region is tropical rainy monsoon type (Köppen 1948; Projeto RadamBrasil 1976). The rainfall has an annual cycle marked by a rainy season, between November and March, and a dry season, between May and

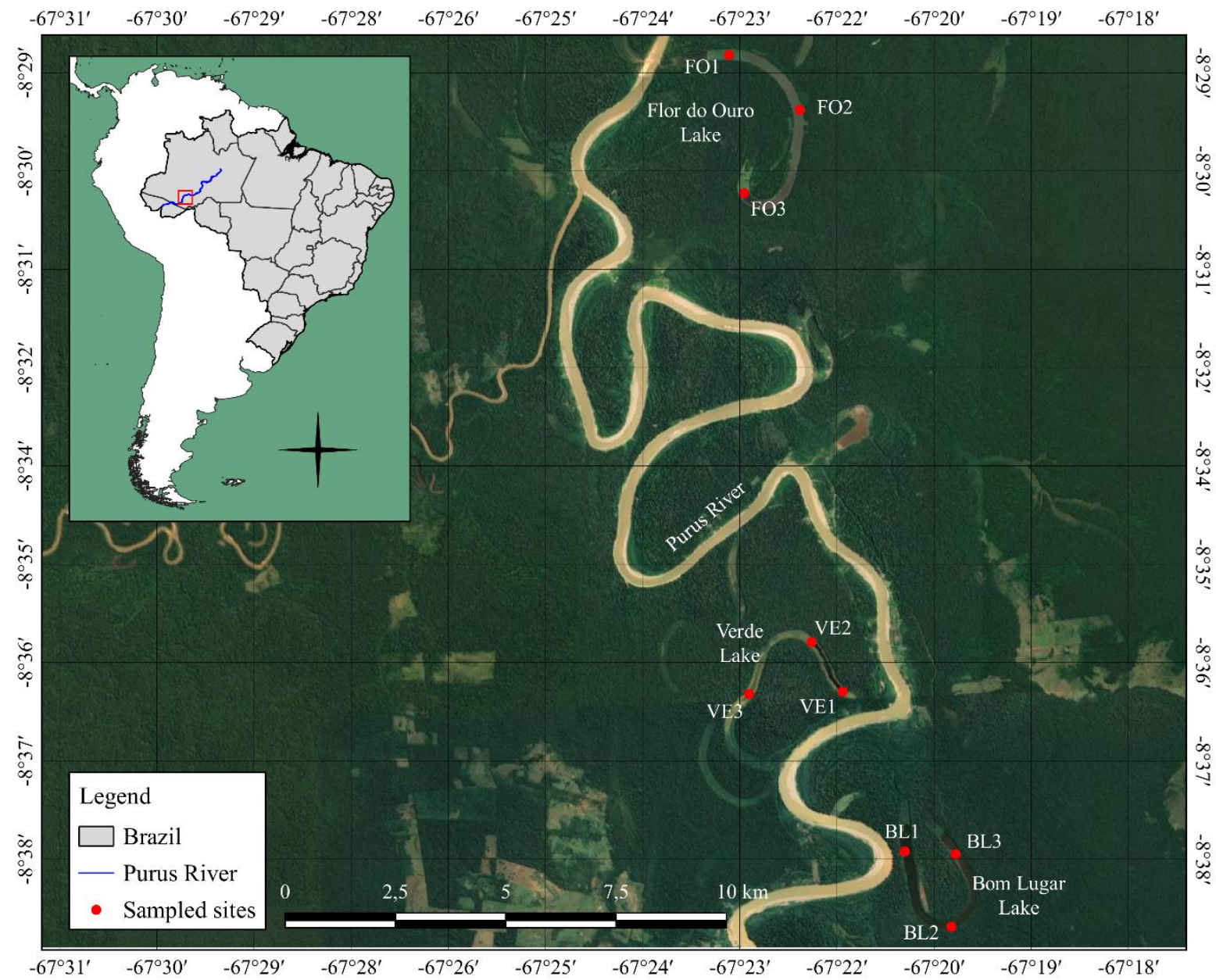

Figure 1. Oxbow lakes sampled in the middle Purus River, Amazon basin, Brazil. Yellow circles indicate the location of the transects sampled in the Flor do Ouro Lake (FO1, FO2, FO3), Verde Lake (VE1, VE2, VE3) and 
137 We surveyed the anuran assemblages, macrophytes and macroinvertebrates in three oxbow lakes in the middle

138 Purus River (Figure 1). The lakes were selected based on the connectivity criteria, in which we used the

139 parameters of lake depth (m), connectivity depth (m), connectivity profile (terrain elevation in meters),

140 connectivity length (m) and permanence of connection of the lake-river over the hydrological cycle. The depth

141 of each lake and its connectivity was measured every $50 \mathrm{~m}$ using an echo-sounder model Eagle Cuda 168 . The

142 connectivity profile and connectivity length were obtained using a portable GPS tool. For the connectivity

143 profile, the elevation was measured every $50 \mathrm{~m}$ to find a proxy of the terrain' variation close to the confluence

144 with the Purus River. These measures were obtained during flood and drought hydrological season for the lakes

145 of high and medium connectivity, and during the flood for the lakes of low connectivity. The oxbow lake

146 categorized as high connectivity (Bom Lugar lake) presented an average depth of $19.1 \pm 6.1 \mathrm{~m}$, connectivity

147 depth of $6.9 \pm 3.8 \mathrm{~m}$, connectivity profile with elevation of $337.4 \pm 18.1 \mathrm{~m}$ asl and connectivity length of 2.172

148 m, remaining connected with the Purus River throughout the flood and drought hydrological cycle. The lake of

149 medium connectivity (Flor do Ouro lake) presented an average depth of $17 \pm 5.4 \mathrm{~m}$, connectivity depth of $7.4 \pm$

$1503.6 \mathrm{~m}$, connectivity profile with elevation of $319.4 \pm 6.1 \mathrm{~m}$ asl and connectivity length of $456 \mathrm{~m}$, remaining

151 partially connected with the river during the drought. The lake of low connectivity (Verde lake) presented an

152 average depth of $8.8 \pm 3.6 \mathrm{~m}$, connectivity depth of $3.8 \pm 5.8 \mathrm{~m}$, connectivity profile with elevation of $371.2 \pm$

$15320.6 \mathrm{~m}$ asl and connectivity length of $305 \mathrm{~m}$, remaining disconnected from the river during the drought

154 hydrological regime (Table 1). Thus, our observations in the field allowed us to infer that the connectivity

155 profile (variation of terrain elevation) is directly related to the degree of connectivity. For example, although the

156 high connectivity lake has longer connectivity and depth of connectivity similar to that of medium connectivity,

157 the lower profile of the terrain along connectivity allows it to remain connected with the river during all

158 hydrological regimes.

159

160 Table 1. Characterization of the oxbow lakes sampled in the middle Purus River, Amazon basin, Brazil, and its respective degree of connectivity.

\begin{tabular}{|c|c|c|c|}
\hline \multirow{2}{*}{ Parameters } & \multicolumn{3}{|c|}{ Oxbow lake } \\
\hline & Bom Lugar & Flor do Ouro & Verde \\
\hline Latitude & 8.38515 & 8.28393 & 8.44361 \\
\hline Longitude & 67.20373 & 67.23290 & 67.22490 \\
\hline
\end{tabular}




\begin{tabular}{llll}
\hline \multirow{2}{*}{ Parameters } & \multicolumn{3}{c}{ Oxbow lake } \\
\cline { 2 - 4 } & Bom Lugar & Flor do Ouro & Verde \\
\hline Lake depth (m) & $19.1 \pm 6.1$ & $17 \pm 5.4$ & $8.8 \pm 3.6$ \\
Connectivity depth (m) & $6.9 \pm 3.8$ & $7.4 \pm 3.6$ & $3.8 \pm 5.8$ \\
Connectivity profile (m asl) & $337.40 \pm 18.08$ & $319.40 \pm 6.08$ & $371.2 \pm 20.64$ \\
Connectivity length (m) & 2.172 & 459 & 305 \\
Time of connectivity & Flood and drought & Flood and early drought & Flood \\
Degree of connectivity & High & Medium & Low \\
\hline
\end{tabular}

162

163 Data collection

164 In each lake, we surveyed the anuran assemblages, floating meadows and macroinvertebrates along three

165 transects, totalizing nine transects in the middle Purus River (Figure 1). The transects were standardized in 200

$166 \mathrm{~m}$ length, with a minimum distance of $1000 \mathrm{~m}$ among them in each lake and chosen according to the availability

167 of floating meadows. We surveyed each transect twice, once during the hydrological regime of drought (8-17

168 July 2017) and once during the flood season (17-25 January 2018).

Environment and food resource availability

171 We evaluated the available environmental resources through the abundance of the macrophytes species in the floating meadows sampled in each transect. The abundance of the macrophyte was visually evaluated by the counting of the coverage percentage of each species within a $0.5 \times 0.5 \mathrm{~m}$ quadrat. Within each $200 \mathrm{~m}$ transect, we conducted a boat sampling at a distance of approximately $10 \mathrm{~m}$ from the edge of the lake and delimited five equidistant points (every $50 \mathrm{~m}$ ) to throw the quadrat, where we throw it five times per point in each survey, totalizing 25 quadrats in each transect. The abundance of macrophyte species obtained for each point were

177 summed up to estimate the total covering in each transect. Macrophyte species were identified according to 178 Guterres et al. (2008), Thiers (2018), SPLink (2018) and Flora do Brasil (2020). The availability of food 179 resources was evaluated through the collection of macroinvertebrates in floating meadows at the same time and at the same points where macrophyte species were sampled along the $200 \mathrm{~m}$ transect. The samplings were carried out using a $4 \mathrm{~m}^{2}$ seine floating net, formed by two cables of $220 \mathrm{~cm}$ length connected to a net of $200 \mathrm{~cm}$ width and $200 \mathrm{~cm}$ length, handled by two researchers. The floating net was pulled in the floating meadows, from the bottom to the surface, seeking the maximum capture of individuals for 10 minutes every $50 \mathrm{~m}$. The 
invertebrate specimens were euthanized with a lethal chamber, using 58\% acetone and fixed in $70 \%$ alcohol.

Anuran surveys and stomach contents analysis

188 The hylid anuran surveys were carried out at the same transects and at the same time of the surveys of macrophytes and macroinvertebrates. We performed the anuran sampling using the active and auditory search methods (Crump and Scott Jr. 1994), always carried out by two researchers on a boat, approximately $10 \mathrm{~m}$ from the edge of the lake. For each anuran individual visualized, the macrophyte species where it was found calling or foraging at the time of collection was registered and named as environmental resource used. The individuals sampled were anesthetized and euthanized with 5\% xylocaine, fixed in 10\% formalin and stored in 70\% alcohol.

194 The stomachs of the collected specimens were removed, the contents were scattered in a Petri dish, counted and analyzed using a stereomicroscope, and subsequently preserved in $1 \mu$ microtubes (Eppendorf) with $70 \%$ alcohol. Food items were identified and categorized to the lowest possible taxonomic level (Hamada, et al. 2014), named as a food resource consumed and used in the following interaction analysis.

\section{Data analysis}

200 We focused our hypothesis in a limited number of species because most species were not prevalent throughout

201 the samples. To test whether the variations in the hylid anuran assemblages are explained mainly by

202 environmental niche and food availability, we built four models referring to each group of predictor variables that could influence the species composition variation in the floating meadows. Thus, models included the environmental niche, available food resources, level of connectivity and hydrological regime. Firstly, in the model of environmental niche we included only macrophyte species that (i) occurred in at least three samples or (ii) showed a coverage percentage $\geq$ equal to or greater than $5 \%$ in at least one sample. For the models of food availability resources, only taxa of macroinvertebrates that (i) occurred in at least three samples or (ii) had total abundance $\geq$ equal to or greater than 20 were considered. Anuran abundance was standardized through Hellinger's transformation (Legendre \& Legendre, 2012). Percentage values of available environmental

210 resources and abundance of available food resources were transformed by calculating the square root and

211 logarithmic function, respectively. The levels of connectivity and hydrological regime were rank-categorized

212 (connectivity: low $=1$, medium $=2$, high $=3$; hydrological regime: drought $=1$, flood $=2$ ). In order to avoid overestimation of the models, the influence of environmental niche and available food resources on the anuran 
214 communities were evaluated by the forward selection procedure, and only the significant variables were selected

215 and included in the RDA (Blanchet et al., 2008). This procedure was performed with 999 iterations for each

216 model and the selection was finalized when the variables had a $P$ value greater than $\alpha=0.05$ (Peres-Neto et al.,

217 2006). We tested the models’ significance using a Redundancy Analysis (RDA) with 999 Monte Carlo

218 iterations. Moreover, we performed a Partial Redundancy Analysis (pRDA) with variance partitioning to

219 evaluate the pure and shared relative contribution of sets of variables to the variation in the hylid anuran

220 assemblages (Dray et al. 2012). Every procedure was performed using the functions available in the packfor

221 (Dray et al. 2013), vegan (Oksanen et al. 2017) and adespatial (Dray et al. 2020) packages in R software ( $\mathrm{R}$

222 Core Team 2020).

In order to examine the interactions between macrophytes, anurans and macroinvertebrates, we used

224 the data obtained from the macrophyte species in which the anuran was collected calling or foraging (the environmental resource used) and the quantitative data on stomach content (food resources consumed), using an approach based on the Theory of Complex Networks. For this, interaction matrices A were constructed, where $\mathrm{a}_{\mathrm{ij}}$ was the number of interactions of an anuran, with macrophyte or macroinvertebrate and 0 where there were no interactions. We obtained 12 matrices corresponding to the interactions of hylid anurans observed in each lake for the attributed category (high, medium and low connectivity) over two different hydrological regimes (flood and drought). Each matrix was divided by the type of interactions, anurans with environmental resources used (macrophyte) or food resource consumed (stomach content; i.e., macroinvertebrates); this for all oxbow lakes and hydrological regimes. Finally, twelve matrices were obtained per lake, six with all interactions between the anurans and macrophytes (environmental resource) in both hydrological regimes (drought and flood), and six with macroinvertebrates (food resource) consumed in both hydrological regimes. For the description of the interactions, we used the following network descriptors: connectance, weighted nestedness (wNODF), modularity and complementary specialization $\left(\mathrm{H}_{2}\right.$ '), similar to the approach used by Ceron et al. (2019). theoretical number of links. This d gives a description of how many interactions are not realized based in the total possible (Jordano 1987). Its values range from 0 to 1,0 indicates that all of potential interactions are not realized and 1 indicates that all the potential interaction in the network is realized. Weighted nestedness, based on the Nestedness Metric, Based on Overlap and Decreasing Fill (NODF), describes the extent to which interactions of specialist species correspond to a subset of generalist interactions (Bascompte et al. 2003). We 
244 calculated the weighted nestedness (wNODF), which is based on the overlap and decreasing fill in the weighted 245 matrix (Almeida-Neto and Ulrich 2011). Nestedness values range from 0 (non-nested network) to 100 (perfect

246 nesting). We also calculated modularity, which measures how groups of species are densely connected and

247 present only sparser connections with other groups of interacting species. We analyzed modularity using the

248 recently implemented LPAwb + algorithm (Liu and Murata 2010; Beckett 2016). Finally, we calculated

249 complementary specialization $\left(\mathrm{H}_{2}{ }^{\prime}\right)$, which is a network-wide index of specialization for quantitative interaction

250 matrices. It describes how species restrict their interactions from those randomly expected based on partner's

251 availability (Blüthgen et al., 2006). The assumption is that if species have preferences for specific interaction

252 partners, these preferences would be captured as a deviation from random encounters given by partner

253 availability (Blüthgen et al. 2006). Values of $\mathrm{H}_{2}$ ' range from 0 to 1 indicating the extremes of generalization and

254 specialization, respectively. The significance of wNODF, modularity, and $\mathrm{H}_{2}$ ' were assessed by comparing them 255 with those obtained for randomized networks generated by a null model based on Patefield’s algorithm

256 (Patefield 1981). We generated 1,000 randomized matrices to estimate the significance of nestedness and 257 complementary specialization and 100 matrices to estimate modularity. To quantify the departure of the

258 observed network values from null expectation, we calculated null-model corrected values by subtracting

259 observed metric value from mean value across all randomized networks ( $\Delta-$ transformation). Then, the $\Delta-$

260 transformed value was divided by the standard deviation of values across all randomized networks ( $\mathrm{z}-$

261 transformation; Dalsgaard et al. 2017; Zanata et al. 2017). All network metrics and null models were calculated

262 with the 'bipartite' ver. 2.08 package (Dormann et al. 2008) in R software (R Core Team 2020).

\section{Results}

\section{Environmental and available food resources}

266 We identified 32 species of macrophytes in the floating meadows, 25 in lakes of high-level connectivity, 20 in medium and 16 in low connectivity. The most abundant macrophyte species were Pistia stratiotes (Araceae)

268 (21\%), Eichhornia crassipes (Pontederiaceae) (16\%) and Ludwigia helminthorrhiza (Onagraceae) (11\%).

269 During the flood, the more abundant macrophyte species were $P$. stratiotes in lakes of high and medium 270 connectivity (42\% and 35\%, respectively) and E. crassipes (34\%) in low connectivity. During the hydrological regime of drought, the more abundant species were $P$. stratiotes $(25 \%)$ in lakes of high connectivity, $E$. crassipes (44\%) in medium, and L. helminthorrhiza (38\%) in low connectivity lakes (Table S1). 
274 were not used in the statistical analyzes. The more abundant invertebrate taxons were Hemiptera (18\%),

275 Orthoptera (17\%) and Diptera (Culicidae, 15\%). The more abundant taxon during the flood hydrological regime 276 in the lake of high connectivity was Hemiptera (24\%), while Orthoptera was more abundant in lakes of medium $277(32 \%)$ and low $(19 \%)$ connectivities. During the drought, the more abundant taxons were Hemiptera in lakes of high $(25 \%)$ and low connectivities (27\%) and Orthoptera in the lake of medium (35\%) connectivity (Table S2).

\section{Effects of environment and available food resources on species abundance}

281 We observed and recorded 741 individuals of five most prevalent hylid anurans in the floating meadows: Boana punctata (129 individuals), Dendropsophus reticulatus (408), Sphaenorhynchus carneus (52), S. dorisae (34) and S. lacteus (118; Table S3). Based on pre-established criteria, we selected 20 macrophyte species (available environmental resource) and 18 macroinvertebrate taxa (available food resource) to compose the RDA models.

285 The model with macrophytes was the most explanatory (72\%) and includes the species Pistia stratiotes, Ceratopteris pteridoides, Lemna minuta and Utricularia gibba. Available food resources explained $57 \%$ of the anuran variation and included the taxa Gastropoda, Odonata, Araneae and Orthoptera. The hydrological regime and connectivity explained $37 \%$ and $16 \%$ of the variation, respectively. In general, the greatest explanation was shared between macrophyte models, food resources and hydrological regime (78\%), where the three groups combined were explained better than individually. The pure explanations were $9 \%$ for macrophytes, $8 \%$ for food resources and $1 \%$ for hydrological regime (Figure 2).

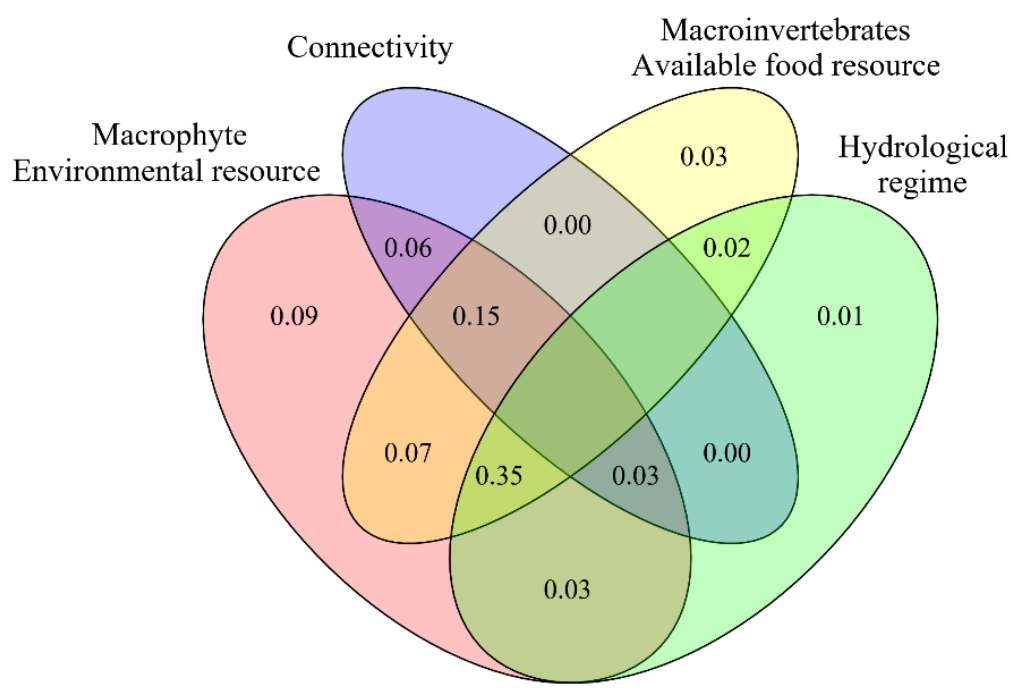

Residuals $=0.23$ 
Figure 2. Variation in anuran abundance explained by environmental resources (macrophyte species), lake connectivity, available food resources (macroinvertebrate taxons) and hydrological regime.

\section{Food items consumed by anurans}

298 Among the individuals registered and collected in the floating meadows, 334 had their had empty stomachs and 407 were used in our analysis, including 47 individuals of Boana punctata, 217 of Dendropsophus reticulatus, 41 of Sphaenorhynchus carneus, 81 of Sphaenorhynchus lacteus and 21 of Sphaenorhynchus dorisae. In relation to food items consumed, Formicidae was the most frequent prey group (29.5\%), followed by Aranea

$302(14.5 \%)$, and Culicidae (7.2\%). During the rainy season, Formicidae was the most frequent prey in lakes of high $(69.1 \%)$, medium $(42.0 \%)$, and low $(69.6 \%)$ connectivity. However, during the dry season, the most consumed prey changed among lakes with different connectivities: Aranae was the most frequent prey consumed in lakes of high $(22.1 \%)$ and medium (28.0\%) connectivity, while Isoptera was most frequent in lakes of low connectivity (25.0\%) (Table S4).

307

\section{Ecological interactions}

309 Network metrics according to regime, connectivity and by the interaction type are shown in Table 2.

310 Connectance showed an increasing trend from high to low connectivity lakes in both interaction types. The

311 higher connectance values were recorded in macrophyte networks during the hydrological regime of drought in

312 lakes with low connectivity $(\mathrm{C}=0.8$; Figure 3$)$. Networks did not show a nested pattern $(\mathrm{p}>0.05$ for all networks). All networks (macrophytes and diet) showed higher trophic specialization and a modular structure,

314 with the exception of the macrophyte network in a flooded lake with low connectivity, and in a lake with medium connectivity during the drought (Figure 3 and Figure 4). The most specialized interactions were

316 recorded in diet networks in the hydrological regime of flood in lakes with medium connectivity $\left(\mathrm{H}_{2}{ }^{\prime}=0.85\right.$;

317 Figure 4). For macrophytes networks, the most specialized interactions were recorded in the hydrological 318 regime of flood in lakes with medium connectivity $\left(\mathrm{H}_{2}{ }^{\prime}=0.41\right)$. Specialization and modularity showed a 319 decrease during the drought for both network types. Modularity was higher in diet networks during flood in 320 lakes with medium connectivity $(\mathrm{M}=0.42)$. For macrophytes networks, modularity was absent or low both in flood or drought (Figure 3 and Figure 4). 
Table 2. Descriptors of networks divided by regime, connectivity and by the interaction between anurans,

324 macrophytes and macroinvertebrates. $Z$-scores values are in parentheses. $\mathrm{M}=$ microhabitat use and $\mathrm{D}=$ diet.

325 Values significantly $(\mathrm{P}<0.05)$ are in bold.

\begin{tabular}{lcccccc}
\hline & \multicolumn{2}{c}{ High } & \multicolumn{2}{c}{ Medium } & \multicolumn{2}{c}{ Low } \\
\hline Flood & $\mathrm{D}$ & $\mathrm{M}$ & $\mathrm{D}$ & $\mathrm{M}$ & $\mathrm{D}$ & $\mathrm{M}$ \\
\hline Connectance & 0.34 & 0.38 & 0.32 & 0.56 & 0.61 & 0.77 \\
Nestedness & 18.18 & 43.83 & 0 & 32 & 16.62 & 66.67 \\
Modularity & $\mathbf{0 . 3 9}(9.63)$ & $\mathbf{0 . 2 7}(6.52)$ & $\mathbf{0 . 4 2}(7.13)$ & $\mathbf{0 . 3 3}(9.2)$ & $\mathbf{0 . 4}(7.55)$ & $0.01(-1.12)$ \\
Specialization & $\mathbf{0 . 6 7}(9.47)$ & $\mathbf{0 . 2 2}(5.68)$ & $\mathbf{0 . 8 5}(10.58)$ & $\mathbf{0 . 4 1}(13.34)$ & $\mathbf{0 . 7 1}(11.36)$ & $0.03(-0.66)$ \\
\hline Drought & $\mathrm{D}$ & $\mathrm{M}$ & $\mathrm{D}$ & $\mathrm{M}$ & $\mathrm{D}$ & $\mathrm{M}$ \\
\hline Connectance & 0.47 & 0.5 & 0.5 & 0.66 & 0.61 & 0.8 \\
Nestedness & 28.12 & 41.4 & 34.21 & 83.33 & 29.37 & 33.75 \\
Modularity & $\mathbf{0 . 2 5}(4.08)$ & $\mathbf{0 . 0 7}(-0.02)$ & $\mathbf{0 . 2 2}(4.04)$ & $0.01(-0.91)$ & $\mathbf{0 . 2 2}(7.25)$ & $\mathbf{0 . 2 8}(7.82)$ \\
Specialization & $\mathbf{0 . 4 6}(5.38)$ & $\mathbf{0 . 1 1}(1.89)$ & $\mathbf{0 . 3 2}(3.03)$ & $0.02(-0.18)$ & $\mathbf{0 . 4 2}(8.87)$ & $\mathbf{0 . 2 7}(9.9)$ \\
\hline
\end{tabular}
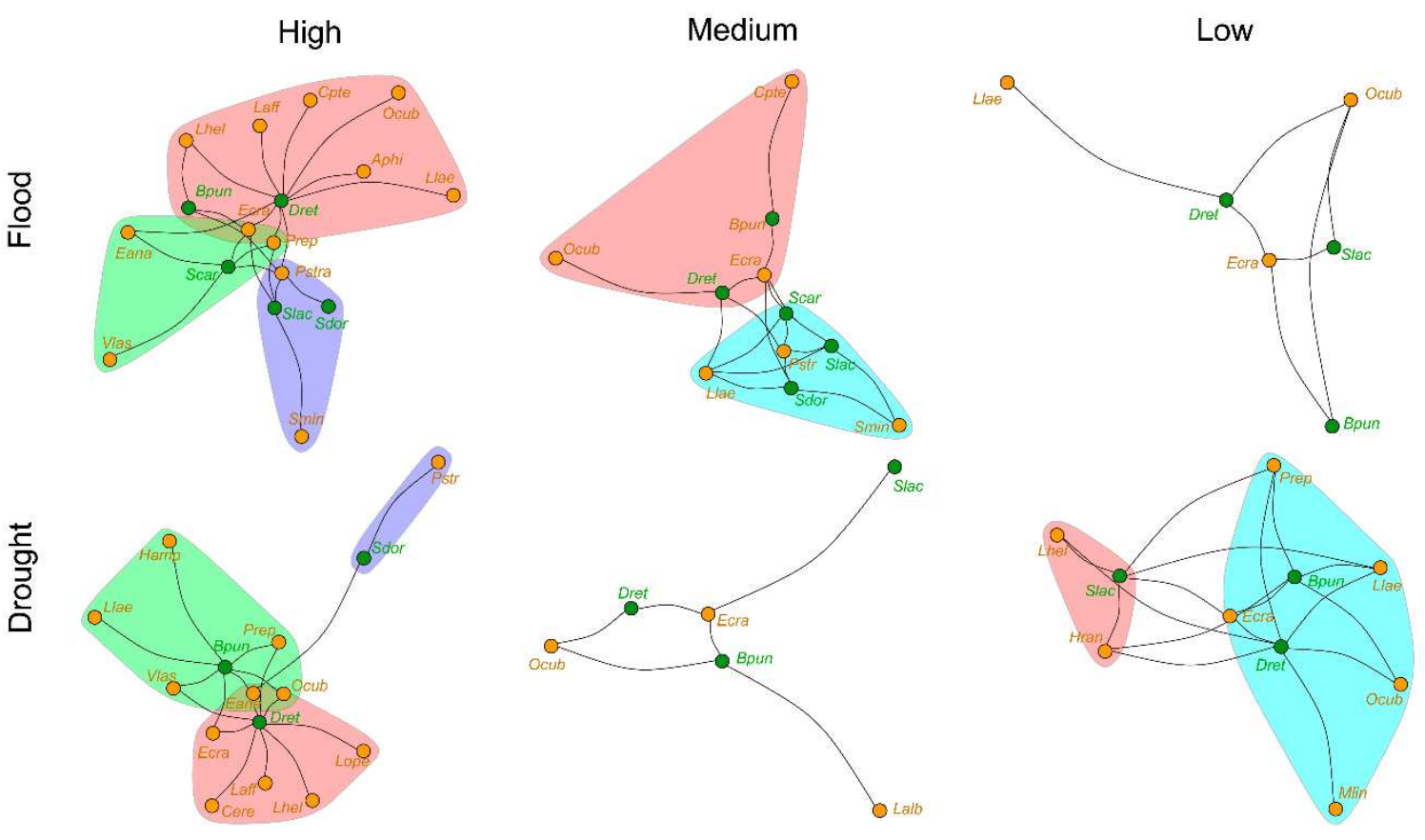

Figure 3. Graphs showing modules (colors) in anuran-macrophyte interactions by lake connectivity (high, medium and low) during the hydrological periods of flood and drought. Circles represent macrophyte (orange) and anuran (green) species. 

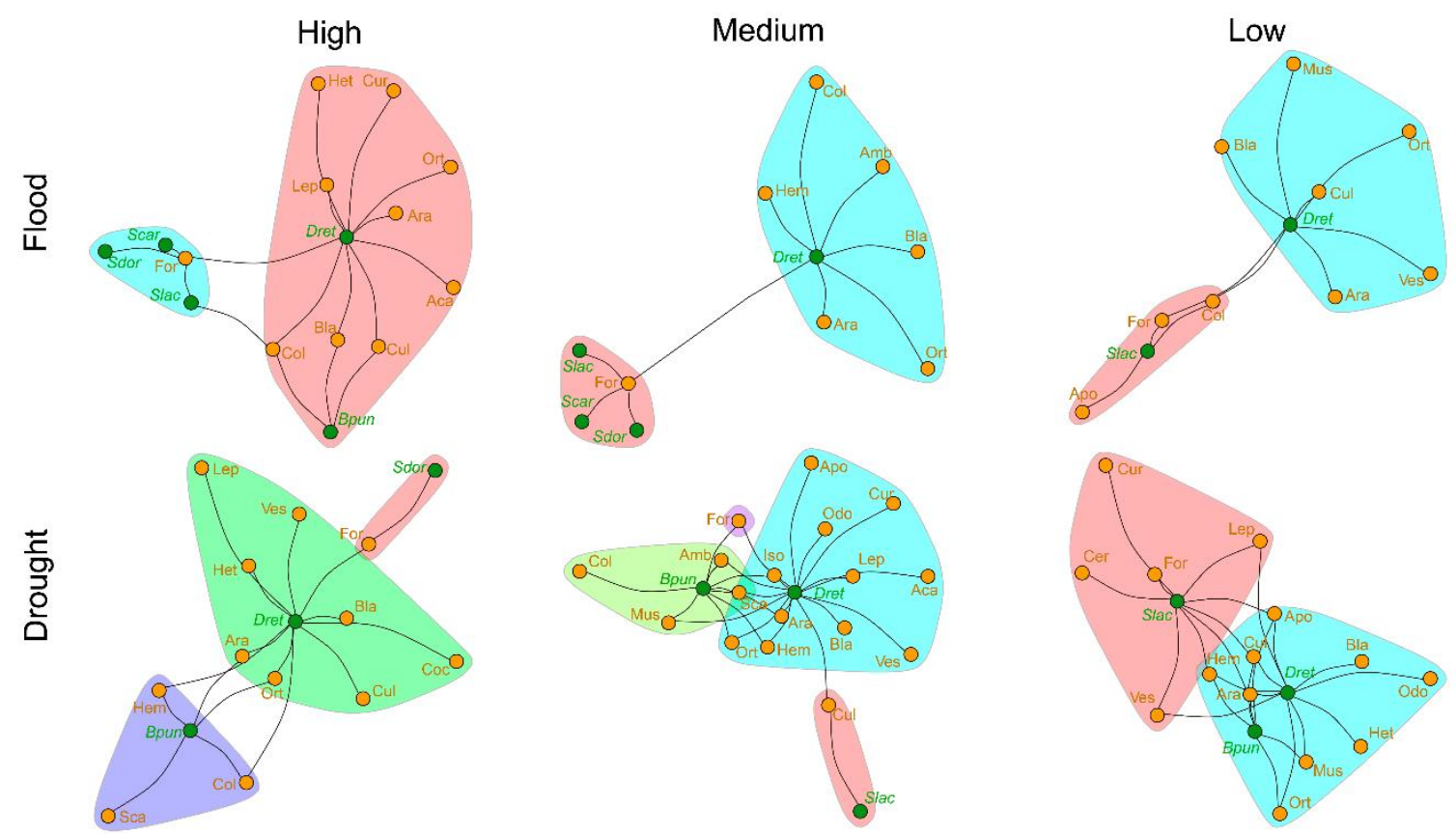

333 Figure 4. Graphs showing modules (colors) in anuran-macroinvertebrate interactions by lake connectivity (high, medium and low) during the hydrological periods of flood and drought. Circles represent prey categories (orange) and anuran species (green).

\section{Discussion}

Our results support our first hypothesis, by showing that the availability of environmental resources (i.e., species of macrophytes) and the availability of food resources (i.e., macroinvertebrates) are the best factors that explain the distribution of hylid anurans. In addition, a high percentage of explanation indicates that the variation in abundance of hylid anurans is highly dependent on the variation in the macrophytes and macroinvertebrates composition between the hydrological regimes. Moreover, our results support the second hypothesis as we found that the connectance, modularity and specialization of anuran, macrophytes and macroinvertebrates networks varies depending on the connectivity and the hydrological regime.

We found that the abundance of the hylid species is influenced by all the factors that we measured (i.e., availability of environment, connectivity, food resource and hydrological regime). However, the availability of

347 the environmental and food resources was the best factor explaining the variation in the abundance of anuran species. Anurans that occur in floating meadows are highly adapted to the open and unstable environment

349 (Ramalho et al., 2018), where species are segregated horizontally and vertically according to their reproductive and foraging requirements (Hödl 1977; Hoogmoed 2013; Upton et al. 2011; Upton et al. 2014). For example, studies in other regions of the Amazon have found that Sphaenorhynchus carneus, S. dorisae and S. lacteus may 

vegetation (e.g., in Paspalum repens) (Hödl 1977; Upton et al. 2011; Upton et al. 2014). These relationships have shown that environmental characteristics of floating meadows (e.g., macrophyte height, macrophyte morphotype composition and water depth) creates a gradient of environmental heterogeneity that acts as a filter in anuran communities (Ganança et al. 2021). Our results indicate that the importance of macrophytes as environmental resources for anurans is complex and varies in space and time, as indicated by the fractions shared between environmental resources, lake-river connectivity and hydrological cycle. reinforce that variation in macroinvertebrates along with the environmental gradient of floating meadows may exert a profound influence on the associated organisms (Poi de Neiff 2003; Peiró and Alves 2006; Upton et al. 2014; Hill et al. 2016). The main macroinvertebrates that explained the variation in hylids were Gastropoda, Odonata, Araneae and Orthoptera, which apparently also interact in a complex way and mediated by specific condition imposed by lake-river connectivity and hydrological cycle. Floating meadows, and macrophyte species as well (as discussed in detail below), are then important foraging sites for anurans, although the complexity of the interactions (e.g., if anurans are predator or prey) still needs to be more explored. Thus, variations in the environmental and food resources directly influence anuran assemblage in floating meadows, indicating a complex structuring by the niche and a non-random pattern in species distribution in space and time.

As expected, the aquatic interactions between anurans, macroinvertebrates and macrophytes showed a modular and specialized structure with no nestedness. Our results showed that the network descriptors among anurans, macroinvertebrates and macrophytes networks vary according to the connectivity and hydrological regime of the lake. Connectance showed an increasing trend from high to low connectivity lakes in both interaction types. This result suggests that anurans are tend to establish more interactions with macrophytes and macroinvertebrates when resources are expected to be more abundant (Thomaz et al. 2009). For specialization, higher values were found in medium connectivity and had a decrease during the drought, both to diet and macrophytes networks. During the drought, when resources are reduced, it is expected that anurans eat and use the resources that are available, reducing specialization and increasing connectance (Emlen 1966; Robinson and Wilson 1998). On the other hand, specialization may be especially favored when resource availability increases, according to predictions of optimal foraging theory (Robinson and Wilson 1998). Therefore, in the flood season, 
when resources are supposedly more abundant in the floodplain, the species of hylids were more selective in terms of food selection and habitat use, so that each species tended to consume specific foods and occupy macrophytes with specific structures. that anurans interact more often with some species of macrophyte. The formation of cohesive groups between anurans and resources could indicate that anurans select the plant where they live and the resources they consume. Therefore, it seems that anurans select fluctuant plants to use, which favors diet and breeding, but the identity of these macrophytes did not strongly interfere with their choices. It is worth to note that the lack of modularity or nestedness in some of the studied networks does not indicate that there could be other interactions pattern within the networks (Guimarães Jr. 2020). The higher values of specialization in diet and macrophytes networks and the high modularity in diet networks, all in medium connectivity, resemble how alpha diversity changes in floodplain systems. Ward and Rockner (2001) proposed that the alpha diversity of several groups reaches a peak in habitats with an intermediate degree of connectivity. This is because the excessive connectivity may keep all communities in pioneer stages or may reduce species diversity if excessive nutrient loading in the river leads to eutrophication of connected floodplain water bodies (Van den Brink et al. 1996; Ward and Tockner, 2001). Thus, in intermediate levels of connectivity the local diversity of macrophytes and preys probably influences the ecological interactions of anurans derived from them. In fact, it has been shown that the main factors structuring ecological networks are the local abundances of interacting species (neutral factors) (Guimarães Jr. 2020). The primary prey of anurans is insects, as well as other arthropods, such as spiders and mites (Simon

402 and Toft 1991; Duellman and Trueb 1994). Each anuran species tended to prefer certain food items and most of 403 the food items consumed by the anurans were available in the floating meadows. The items consumed by the 404 anuran species in this study corroborates the diet described for the species (Duellman 1978, 2005; Lopez et al. 405 2009). However, by implementing a network approach we were able to assess the changes in diet of anurans by 406 changes in habitat connectivity. In this case, we found that in lakes with low connectivity, anurans had a less 407 diversified diet. This evidence suggests that dispersion and therefore habitat connectivity are factors that 408 structure the anuran and its partners in all lakes, as expected by the Neutral theory of diversity (Hubbel 2001), in 409 which the movement of species is one of the factors explaining species local abundance, for example. Variations in the availability of environmental resources (macrophytes) and food resources

411 (macroinvertebrates) were influenced by the connectivity of the lakes and hydrological regimes, affecting the 
412 abundance and structure of interactions of hylid anurans. The interactions found showed that the species use the

413 same resources, which are available in the floating meadows for their consumption, and although they are more

414 generalist, some species use resources more specifically than others. These results show that the hylids

415 associated with floating meadows in this study have their distribution affected by the interaction to both

416 macrophyte and macroinvertebrate species, as well as to lake connectivity level and hydrological regimes. These

417 alterations in the environmental niche affect the anurans associated with floating meadows and show the

418 importance of this environment for biodiversity.

419

\section{Declarations}

421 Funding - This study was financed in part by the Coordenação de Aperfeiçoamento de Pessoal de Nível

422 Superior - Brasil (CAPES), which granted scholarships to WPR (proc. 88882.448043/2019-01), LRAM, FVA

423 and KC, and by the Programa de Pós-Graduação em Ecologia e Manejo de Recursos Naturais which provided

424 financial support via Programa de Apoio à Pós-Graduação (PROAP).

425

426 Acknowledgments - We thank the CAPES (Coordenação de Aperfeiçoamento de Pessoal de Nível Superior) for 427 scholarships awarded, the Programa de Pós-Graduação em Ecologia e Manejo de Recursos Naturais for 428 financial support via PROAP; to Ednelson for the excellent work as a boatman and local guide, the local 429 residents for the housing and support in the collections, and the graduate students Programa de Pós-Graduação 430 em Ecologia e Manejo de Recursos Naturais of the Universidade Federal do Acre for helping during fieldwork.

431 P. Luna wishes to thank Consejo Nacional de Ciência and Technology for scholarship (71366). FVA thanks

432 CNPQ by PCI-MCTIC/MPEG (302198/2020-2).

433

434 Conflicts of interest/Competing interests - Authors declare that they have no conflict of interest.

436 Availability of data and materials - All data produced from this study are provided in this manuscript.

438 Author contributions - All authors contributed to the conceptualization and design of the project. LRAM and

439 WPR collected the data, performed the data analysis, and led the writing of the text. FVA, KC, and PL provided

440 additional expertise on interaction network, performed the data analysis, and wrote the text. LRV provided

441 additional expertise on hydrology and river-lake connectivity. LJSV assisted with data interpretation and 
442 writing, and supervised this research. All authors critiqued the manuscript and gave final approval for

443 submission.

444

445 Consent to Participate - Not applicable.

446

447 Consent for Publication - Not applicable.

448

449 Ethics Approval- This study follows the guidelines and permission to handle and collect animals given by the

450 Ministério do Meio Ambiente / Instituto Chico Mendes de Conservação da Biodiversidade (\#57791-1).

451

452 References

453 Almeida-Neto M, Guimaraes P, Guimaraes PR, Loyola RD, Ulrich W (2008) A consistent metric for nestedness

454 analysis in ecological systems: reconciling concept and measurement. Oikos 117:1227-1239

455 Angelis CF. Waichaman AV, Silva AEP, Machado LAT (2008) Influência da precipitação na qualidade da água do Rio Purus. Acta Amaz 38:733-742

457 Bascompte J, Jordano P, Melián CJ, Olesen JM (2003) The nested assembly of plant-animal mutualistic 458 networks. Proc Natl Acad Sci U. S. A. 100(16):9383-9387

459 Beckett SJ (2016) Improved community detection in weighted bipartite networks. R Soc Open Sci 3:140536.

460 https://doi.org/10.1098/rsos.140536

461 Begon M, Harper JL, Townsend CR (2006) Ecology: From individuals to ecosystems. 4 ed. Oxford: Blackwell

$462 \quad$ Publishing. pp.759

Blanchet FG, Legendre P, Borcard D (2008) Forward selection of explanatory variables. Ecology 89: 2623-2632

464

Blüthgen N, Menzel F, Blüthgen N (2006) Measuring specialization in species interaction networks. BMC

Ecology, 6. http://dx.doi.org/10.1186 / 1472-6785-6-9

466 Böning P, Wolf S, Upton K, Menin M, Venegas PJ, Lötters S (2017) Amphibian diversity and its turnover in

467 floating meadows along the Amazon river. Salamandra 53(3):379-388 
Dalsgaard B, Schleuning M, Maruyama PK, Dehling DM, Sonne J, Vizentin-Bugoni, J. Zanata T.B, Fjeldså J,

Dray S, Bauman D, Blanchet G, Bocard D, Clappe S, Guenard G, Jombart T, Larocque G, Legendre P, Madi N,

479 Wagner HH (2020) adespatial: Multivariate Multiscale Spatial Analysis. R package version 0.3-8. https://CRAN.R-project.org/package=adespatial

481 Dray S, Legendre P, Blanchet G (2016) packfor: Forward Selection with permutation (Canoco p.46). R package 482 version 0.0-8/r136. https://R-Forge.R-project.org/projects/sedar/

483 Dray S, Pélissier R, Couteron P, Fortin MJ, Legendre P, Peres-Neto P.R, Bellier E. Bivand R, Blanchet FG,

484 Cáceres M, Dufour AB, Heegaard E, Jombart T Munoz F, Oksanen J. Thioulouse J, Wagner HH (2012)

485 Community ecology in the age of multivariate multiscale spatial analysis. Ecol. Monographs 82.

486 https://doi.org/10.1890/11-1183.1

487 Duellman WE (1978) The biology of an Equatorial herpetofauna in Amazonian Ecuador. University of Kansas, Lawrence, Kansas. pp.352

489 Duellman WE (2005) Cusco Amazónico: The lives of Amphibians and Reptiles in an Amazonian Rainforest. 490 Cornell University Press. pp.472 
494 Flora do Brasil (2020) Jardim Botânico do Rio de Janeiro. Disponível em: < http://floradobrasil.jbrj.gov.br/ >.

495 Acesso em: 30 set. 2020

496 Ganança PHS, Santos Jr., Kawashita-Ribeiro RA, Vasconcelos Neto LB, Santos Júnior IA, Guedes DS; de

497 Fraga DSG (2021) Habitats determining local frog assemblages within aquatic macrophyte meadows in

498 Amazonia, through species traits filtering. Austral Ecol 46(4):574-587

499 Guimarães Jr. (2020) The Structure of Ecological Networks Across Levels of Organization. Annu Rev Ecol

500 Evol Syst 51:433-460

501 Guterres MG, Marmontel M, Ayub DM, Singer RF, Singer RB (2008) Anatomia E Morfologia Des Plantas

502 Aquáticas Da Amazônia (Utilizadas Como Potencial Alimento Por Peixe-Boi Amazônico). Belem/Pa; $1^{\mathrm{a}}$ Edição

503 Hamada N, Nessimian JL, Querino RB (2014) Insetos aquáticos na Amazonia brasileira: taxonomia, biologia e

504 ecologia/Editores Neusa Hamada, Jorge Luiz Nessimian, Ranyse Barbosa Querino. Manaus: Editora do INPA.

505 pp.724

506 Hill MJ, Biggs J, Thornhill I, Briers RA, Gledhill DG, White JC, Woord PJ, Hassall C (2016) Urban ponds as

507 an aquatic biodiversity resource in modified landscapes. Glob Change Biol 23(3) 986-999

508 Hödl W (1977) Call differences and calling site segregation in Anuran Species from central Amazonian floating

509 meadows. Oecologia 28:351-563

510 Hoogmoed MS (1993) The herpetofauna of floating meadows. In: Ouboter P.E. (eds) The Freshwater

511 Ecosystems of Suriname. Monographiae Biologicae. Springer, Dordrecht Academic Publishers, pp.199-213

512 Hubbell SP (2001) The Unified Neutral Theory of Biodiversity and Biogeography, Princeton University Press.

513 pp.392

514 Jordano P (1987) Patterns of mutualistic interactions in pollination and seed dispersal: connectance, dependence

515 asymmetries and coevolution. Amer Nat 129: 657-677 
516 Junk WJ, Bayley PB, Sparks RE (1989) The flood pulse concept in river-floodplain systems. In: Dogde, Dp.

517 Proceedings of the International Large River Symposium, Special Publications on Canadian Fishery and

518 Aquatic Sciences. 1989, pp.110-127.

519 Junk WJ, Piedade MTF, Lourival R, Wittmann F, Kandus P, Lacerda LD, Bozelli RL, Esteves FA, Nunes Da

520 Cunha C, Maltchik L, Schöngart J, Schaeffernovelli Y, Agostinho AA (2014) Brazilian wetlands: their

521 definition, delineation, and classification for research, sustainable management, and protection. Aquatic

522 Conservation: Marine and Freshwater Ecosystems 24:5-22

523 Köppen W (1948) Climatologia: Com um estudio de los climas de la tierra. Fondo de Cultura Econômica,

524 México. pp.127-144

525 Legendre P, Legendre L (2012) Numerical Ecology. Elsevier, Amsterdam. pp.1006.

526 Liu X, Murata T (2010) Advanced modularity-specialized label propagation algorithm for detecting

527 communities in networks. - Physica A: Statistical Mechanics and its Applications 389:1493-1500

528 López JA, Scarabotti PA, Medrano MC, Ghidardi R (2009) Is the red spotted green frog Hypsiboas punctatus 529 (Anura: Hylidae) selecting its preys? The importance of prey availability. Rev de Biolo Trop 57:847-857

530 Luz-Agostinho KDG, Agostinho AA, Gomes LC, Júlio HF, Fugi R (2009) Effects of flooding regime on the 531 feeding activity and body condition of piscivorous fish in the Upper Paraná River floodplain. Braz J of Biol $532 \quad 69: 481-490$

533 MacDonald AAM, Banville F, Poisot T (2020) Revisiting the Links-Species Scaling Relationship in Food 534 Webs. Patterns 1(7): 100079

535 Mormul RP, Thomaz SM, Vieira LJS (2013) Richness and composition of macrophyte assemblages in four 536 Amazonian lakes. Acta Sci Biol Sci 35(3): 343-350

537 Moura Júnior E G, Paiva R MS, Ferreira A C, Pacopahyba L D, Tavares A S, Ferreira F A, Pott A (2015)

538 Updated checklist of aquatic macrophytes from Northern Brazil. Acta Amaz 45 (2):111-132

539 Olesen J M, Jordano P (2002) Geographic patterns in plant-pollinator mutualistic networks. - Ecology

$540 \quad 83: 2416-2424$ 
541 Patefield WM (1981) Algorithm AS 159: an efficient method of generating random $\mathrm{R} \times \mathrm{C}$ tables with given row

542 and column totals. J R Stat Soc 30:91-97

543 Peiró DF, Alves RG (2006) Insetos aquáticos associados a macrófitas da região litoral da represa do Ribeirão

544 das Anhumas (município de Américo Brasiliense, São Paulo, Brasil). Biota Neotr 6:1-9

545 Pelicice FM, Agostinho AA (2006) Feeding ecology of fishes associated with Egeria spp. patches in a tropical

546 reservoir. Brazil Ecol of Fresh Fish 15:10-19

547 Peres-Neto PR, Legendre P, Dray S, Borcard D (2006) Variation partitioning of species data matrices:

548 estimation and comparison of fractions. Ecology 87(10):2614-2625

549 Petry P, Bayley PB, Markle DF (2003) Relationships between fish assemblages, macrophytes and

550 environmental gradients in the Amazon River floodplain. J of Fish Biol 63:547-579

551 Petsch DK (2016) Causes and consequences of biotic homogenization in freshwater ecosystems. Inter Rev of 552 Hydro 101:113-122

553 Poi de Neiff A (2003) Macroinvertebrates living on Eichhornia azurea Kunth in the Paraguay River. Acta

554 Limnologica Brasiliensia 15(1): 55-63.

555 Projeto Radambrasil. Folha SC (1976) 19 Rio Branco: geologia, geomorfologia, pedologia, vegetacao, uso

556 potencial da terra. Rio de Janeiro: Departamento Nacional da Produção Mineral, (Levantamento de recursos

557 naturais, 12). Pp.457

558 R Core Team. 2020. R: A language and environment for statistical computing. R Foundation for Statistical

559 Computing, Vienna, Austria. https://www.R-project.org/.

560 Ramalho W. P, Machado I F, Vieira LJ S (2018) Do flood pulses structure amphibian communities in floodplain environments? Biotropica, 50:338-345 meadows of the oxbow lakes of the Middle Purus River, Amazonas, Brazil. Biota Neotr 16, 1-15 desmatamento na bacia do rio Purus, Amazônia brasileira Ocidental. Rev Geo Acad 5:54-56 
Scarabotti PA, López JA, Pouilly M (2011) Flood pulse and the dynamics of fish assemblage structure from neotropical floodplain lakes. Ecol Freshw Fish 20:605-618

571 Macrophyte rafts as dispersal vectors for fishes and amphibians in the Lower Solimões River, Central Amazon.

576 SPLink (2018) Centro de Referência em Informação Ambiental, CRIA - Fundação de Amparo à Pesquisa do

577 Estado de São Paulo, (www.splink.cria.org.br). Acessado em 25/09/2018.

578 St. Pierre JI, Kovalenko KE (2014) Effect of habitat complexity attributes on species richness. Ecosphere $579 \quad 5(2): 1-10$

580 Thiers B (2018) Index Herbariorum: A global directory of public herbaria and associated staff. New York Botanical Garden's Virtual Herbarium. (http://sweetgum.nybg.org/science/ih/). Acessado em 14/11/2018. systems. Hydrobiologia 579, 1-13

584 Tylianakis J M, Morris RJ (2017) Ecological networks across environmental gradients. Annu Rev Ecol Evol S, $585 \quad 48: 25-48$

586 Upton K, Warren-Thomas E, Rogers I, Docherty E (2014) Amphibian diversity on floating meadows in flooded forests of the Peruvian Amazon. Herpet. Rev. 45, 209-212 
590 Van Den Brink FWB, Van Der Velde G, Buijse AD, Klink AG (1996) Biodiversity of the Lower Rhine and

591 Meuse river-floodplains: its significance for ecological management. Netherlands Journal of Ecology 30: 129-

592149.

593 Ward JV, Tockner L (2001) Biodiversity: towards a unifying theme for river ecology. Freshw Biol 46:807-819

594 Zanata TB, Dalsgaard B, Passos FC et al. 2017. Global patterns of interaction specialization in bird-flower

595 networks. J. Biogeogr 44:1891-1910

596 
597 Supplementary Information

598 Table S1. Relative abundance of macrophyte species found in three oxbow lakes of different

599 connectivity during the flood and drought hydrological regime in the middle Purus River,

600 Amazon basin, Brazil.

\begin{tabular}{|c|c|c|c|c|c|c|c|}
\hline \multirow{2}{*}{ Taxon } & \multicolumn{2}{|c|}{ High connectivity } & \multicolumn{2}{|c|}{ Medium connectivity } & \multicolumn{2}{|c|}{ Low connectivity } & \multirow{2}{*}{$\begin{array}{l}\text { Relative } \\
\text { abundance }\end{array}$} \\
\hline & Flood & Drought & Flood & Drought & Flood & Drought & \\
\hline \multicolumn{8}{|l|}{ Amaranthaceae } \\
\hline Alternanthera philoxeroides & 0.25 & 0.19 & & & & & 0.08 \\
\hline \multicolumn{8}{|l|}{ Araceae } \\
\hline Lemna minuta & 7.80 & 3.89 & 5.89 & 10.98 & 0.17 & 0.96 & 4.78 \\
\hline Pistia stratiotes & 42.28 & 24.73 & 34.55 & 11.24 & 4.94 & & 20.86 \\
\hline Wolffiela lingulata & 0.15 & 0.17 & 0.19 & & & 2.03 & 0.42 \\
\hline \multicolumn{8}{|l|}{ Araliaceae } \\
\hline Hydrocotyle ranunculoides & & & 1.69 & 0.67 & 4.51 & 28.00 & 5.58 \\
\hline \multicolumn{8}{|l|}{ Asteraceae } \\
\hline Eclipta prostrata & 0.70 & 0.67 & & & & & 0.26 \\
\hline Enydra anagallis & 5.35 & 22.94 & & 0.60 & & 0.12 & 5.54 \\
\hline Gymnocoronis spilanthoides & & & 0.48 & & & & 0.08 \\
\hline Mikania scandens & & & & & 2.64 & 2.32 & 0.80 \\
\hline \multicolumn{8}{|l|}{ Commelinaceae } \\
\hline Commelina erecta & & 0.19 & & & & & 0.04 \\
\hline \multicolumn{8}{|l|}{ Cucurbitaceae } \\
\hline Luffa operculata & & 0.29 & & & & & 0.06 \\
\hline \multicolumn{8}{|l|}{ Cyperaceae } \\
\hline Oxycaryum cubense & 1.28 & 2.27 & 7.35 & 20.66 & 17.14 & 6.99 & 8.42 \\
\hline \multicolumn{8}{|l|}{ Euphorbiaceae } \\
\hline Caperonia castaneifolia & & & 0.40 & & & & 0.07 \\
\hline \multicolumn{8}{|l|}{ Fabaceae } \\
\hline Mimosa pigra & & & & 0.19 & & & 0.02 \\
\hline
\end{tabular}




\begin{tabular}{|c|c|c|c|c|c|c|c|}
\hline \multirow{2}{*}{ Taxon } & \multicolumn{2}{|c|}{ High connectivity } & \multicolumn{2}{|c|}{ Medium connectivity } & \multicolumn{2}{|c|}{ Low connectivity } & \multirow{2}{*}{$\begin{array}{l}\text { Relative } \\
\text { abundance }\end{array}$} \\
\hline & Flood & Drought & Flood & Drought & Flood & Drought & \\
\hline Vigna lasiocarpa & 0.73 & 4.10 & 0.95 & & & & 1.10 \\
\hline \multicolumn{8}{|l|}{ Hydrocharitaceae } \\
\hline Limnobium laevigatum & 2.69 & 7.84 & 5.51 & & 2.81 & 4.00 & 4.08 \\
\hline \multicolumn{8}{|l|}{ Lentibulariaceae } \\
\hline Utricularia gibba & 2.06 & 1.48 & 3.63 & 0.04 & 8.75 & 4.38 & 3.42 \\
\hline \multicolumn{8}{|l|}{ Onagraceae } \\
\hline Ludwigia affinis & 1.10 & 0.38 & & & & & 0.28 \\
\hline Ludwigia helminthorrhiza & 6.10 & 8.77 & & & 16.07 & 37.94 & 11.49 \\
\hline Ludwigia leptocarpa & & & 0.42 & & & & 0.07 \\
\hline \multicolumn{8}{|l|}{ Passifloraceae } \\
\hline Passiflora $s p$ & 1.03 & & 0.16 & & & & 0.22 \\
\hline \multicolumn{8}{|l|}{ Phyllanthaceae } \\
\hline Phyllanthus fluitans & 0.10 & & & & & & 0.02 \\
\hline \multicolumn{8}{|l|}{ Poaceae } \\
\hline Bracharia purpurascens & 0.40 & & & & & & 0.07 \\
\hline Hymenachne amplexicaulis & & 0.36 & & & & & 0.07 \\
\hline Panicum aquaticum & & & & & 0.46 & & 0.07 \\
\hline Paspalum repens & 5.45 & 3.89 & 0.21 & & 2.32 & 7.88 & 3.43 \\
\hline \multicolumn{8}{|l|}{ Pontederiaceae } \\
\hline Eichhornia crassipes & 13.65 & 0.72 & 10.25 & 43.73 & 34.18 & 5.22 & 16.25 \\
\hline \multicolumn{8}{|l|}{ Pteridaceae } \\
\hline Ceratopteris pteridoides & 1.13 & 6.03 & 0.48 & 4.88 & & & 2.07 \\
\hline \multicolumn{8}{|l|}{ Ricciaceae } \\
\hline Ricciocarpus natans & & 2.77 & & & & 0.03 & 0.54 \\
\hline \multicolumn{8}{|l|}{ Salviniaceae } \\
\hline Azolla filiculoides & 1.13 & 0.14 & 8.29 & 0.04 & 4.74 & 0.14 & 2.48 \\
\hline Salvinia auriculata & 1.03 & 0.86 & 1.54 & & & & 0.63 \\
\hline Salvinia minima & 5.60 & 7.34 & 18.03 & 7.00 & 1.26 & & 6.69 \\
\hline
\end{tabular}


601

602 
603 Table S2. Abundance of macroinvertebrates found in three oxbow lakes of different

604 connectivity during the flood and drought hydrological regime in the middle Purus River,

605 Amazon basin, Brazil.

\begin{tabular}{|c|c|c|c|c|c|c|c|}
\hline \multirow{2}{*}{ Taxon } & \multicolumn{2}{|c|}{ High connectivity } & \multicolumn{2}{|c|}{ Medium connectivity } & \multicolumn{2}{|c|}{ Low connectivity } & \multirow{2}{*}{$\begin{array}{l}\text { Relative } \\
\text { abundance }\end{array}$} \\
\hline & Flood & Drought & Flood & Drought & Flood & Drought & \\
\hline Acarina & 1 & 10 & & 3 & 5 & 1 & 0.49 \\
\hline Araneae & 44 & 109 & 32 & 95 & 25 & 95 & 9.90 \\
\hline Blattodea & 14 & 11 & 2 & 4 & & 15 & 1.14 \\
\hline Coccinellidae & 4 & & 2 & & 2 & 2 & 0.25 \\
\hline Coleoptera & 47 & 22 & 58 & 25 & 119 & 16 & 7.10 \\
\hline Curculionidae & 11 & 32 & 7 & 7 & 64 & 21 & 3.51 \\
\hline Diptera (Culicidae) & 90 & 67 & 10 & 66 & 149 & 211 & 14.67 \\
\hline Diptera (Muscidae) & 85 & 39 & 6 & 16 & 61 & 69 & 6.83 \\
\hline Gastropoda & 11 & 4 & 17 & & 18 & 9 & 1.46 \\
\hline Gerridae & & 4 & & & & & 0.10 \\
\hline Hemiptera & 170 & 195 & 7 & 20 & 86 & 237 & 17.69 \\
\hline Heteroptera & 61 & 75 & 25 & 13 & 78 & 40 & 7.23 \\
\hline Hymenoptera (Apoidea) & & 1 & 1 & & 1 & 2 & 0.12 \\
\hline Hymenoptera (Formicidae) & 105 & 40 & 24 & 12 & 17 & 4 & 5.00 \\
\hline Larva & 9 & & & & 36 & 7 & 1.29 \\
\hline Lepidoptera & 6 & 9 & 1 & 3 & 3 & 3 & 0.62 \\
\hline Mantodea & & 4 & & & & & 0.10 \\
\hline Odonata & 1 & 2 & 1 & & 7 & 10 & 0.52 \\
\hline Orthoptera & 42 & 141 & 102 & 178 & 163 & 60 & 16.98 \\
\hline Scarabaeidae & & 9 & 19 & 61 & 14 & 62 & 4.08 \\
\hline Trichoptera & & & & & & 8 & 0.20 \\
\hline Vespidae & 8 & 3 & 4 & 3 & 2 & 9 & 0.72 \\
\hline Total Geral & 709 & 777 & 318 & 506 & 850 & 881 & 100.00 \\
\hline
\end{tabular}


608 Table S3. Hylid species collected in three oxbow lakes of different connectivity during the

609 flood and drought hydrological regime in the middle Purus River, Amazon basin, Brazil.

\begin{tabular}{|c|c|c|c|c|c|c|c|}
\hline \multirow{2}{*}{ Species } & \multicolumn{2}{|c|}{ High connectivity } & \multicolumn{2}{|c|}{ Medium connectivity } & \multicolumn{2}{|c|}{ Low connectivity } & \multirow{2}{*}{$\begin{array}{c}\text { Total } \\
\text { abundance }\end{array}$} \\
\hline & Flood & Drought & Flood & Drought & Flood & Drought & \\
\hline Boana punctata & 6 & 39 & 8 & 26 & 16 & 34 & 129 \\
\hline Dendropsophus reticulatus & 54 & 106 & 78 & 55 & 33 & 82 & 408 \\
\hline Sphaenorhynchus carneus & 31 & 0 & 0 & 0 & 21 & 0 & 52 \\
\hline Sphaenorhynchus dorisae & 10 & 2 & 0 & 0 & 22 & 0 & 34 \\
\hline Sphaenorhynchus lacteus & 20 & 0 & 48 & 33 & 16 & 1 & 118 \\
\hline Total abundance & 121 & 147 & 134 & 114 & 108 & 117 & 741 \\
\hline
\end{tabular}

610

611 
612 Table S4. Food items consumed by five hylid species in three oxbow lakes of different

613 connectivity during the flood and drought hydrological regime in the middle Purus River,

614 Amazon basin, Brazil.

\begin{tabular}{|c|c|c|c|c|c|c|c|}
\hline \multirow{2}{*}{ Taxon } & \multicolumn{2}{|c|}{ High connectivity } & \multicolumn{2}{|c|}{ Medium connectivity } & \multicolumn{2}{|c|}{ Low connectivity } & \multirow{2}{*}{$\begin{array}{l}\text { Total } \\
\text { frequency }\end{array}$} \\
\hline & Flood & Drought & Flood & Drought & Flood & Drought & \\
\hline Acari & 1 & 0 & 0 & 0 & 0 & 1 & 2 \\
\hline Amblypgi & 0 & 0 & 0 & 0 & 2 & 9 & 11 \\
\hline Apoidae & 0 & 0 & 3 & 4 & 0 & 1 & 8 \\
\hline Araneae & 3 & 15 & 3 & 26 & 5 & 13 & 65 \\
\hline Blattodea & 3 & 8 & 2 & 3 & 2 & 4 & 22 \\
\hline Cerambicidae & 0 & 0 & 0 & 2 & 0 & 0 & 2 \\
\hline Coccinellidae & 0 & 1 & 0 & 0 & 0 & 0 & 1 \\
\hline Coleoptera & 3 & 3 & 8 & 0 & 1 & 1 & 16 \\
\hline Curculionidae & 1 & 0 & 0 & 1 & 0 & 1 & 3 \\
\hline Culicidae & 3 & 3 & 10 & 13 & 0 & 3 & 32 \\
\hline Elateridae & 0 & 0 & 0 & 0 & 0 & 0 & 0 \\
\hline Formicidae & 47 & 8 & 21 & 21 & 32 & 3 & 132 \\
\hline Heteroptera & 1 & 5 & 0 & 3 & 0 & 0 & 9 \\
\hline Hemiptera & 0 & 7 & 0 & 6 & 3 & 5 & 21 \\
\hline Isoptera & 0 & 0 & 0 & 0 & 0 & 23 & 23 \\
\hline Lepidoptera & 5 & 1 & 0 & 2 & 0 & 4 & 12 \\
\hline Muscidae & 0 & 0 & 1 & 6 & 0 & 3 & 10 \\
\hline Odonata & 0 & 0 & 0 & 1 & 0 & 3 & 4 \\
\hline Orthoptera & 1 & 12 & 1 & 3 & 1 & 4 & 22 \\
\hline Scarabaeidae & 0 & 2 & 0 & 0 & 0 & 13 & 15 \\
\hline Vespidae & 0 & 3 & 1 & 2 & 0 & 1 & 7 \\
\hline
\end{tabular}

615

616 